\title{
Religious Practice among Italian Youth: A Case Study in Lazio
}

\author{
Lucio Meglio \\ Department of Social Science, University of Cassino, Cassino, Italy \\ Email: l.meglio@unicas.it
}

Received February 21 $1^{\text {st }}, 2012$; revised March $18^{\text {th }}, 2012$; accepted April $5^{\text {th }}, 2012$

\begin{abstract}
The purpose of this article will be to highlight, through a case study of the Lazio region of Italy to the south of Rome, of the changing role of religion in Western Europe according to recent analyses that have been carried out on the relationship between religion and identity among young people, and the relationship between family structure and composition and religious practices. These issues have also been the topic of discussion among Catholic and Protestant groups in the different member countries and have been a controversial topic in the approval of the European Constitutional Treaty. These issues will be assessed in light of the different meanings of religion in non-European countries, especially in the context of underdevelopment in Africa, where there is not a sharp distinction between religious loyalty and civil society. Belonging to one religion or another tends to affect different types of political and economic loyalties, whereas these are maintained as separate spheres of life in Europe due to its heritage of prolonged civil and religious wars. The article will conclude by pointing out the strong potential for renovation that is implicit in religion - a renovation of values and styles of everyday life that seems to be urgent and necessary to face many dilemmas and problems of contemporary Western life. In this respect, a case will be made that religion can help better than politics and political movements to overcome difficulties and resistances in the necessary adaptation to changing environmental and economic conditions.
\end{abstract}

Keywords: Italian Youth; Religious Practice; Values; Generation

\section{Youngsters and Religious Practice: Theoretical Background}

If lay, or broadly secularized, societies are currently referred to in many European countries, reference to the Catholic religion in Italy is still very much diffused. For more than thirty years this same religious universe has been re-proposed, even though elements of extreme decline have been registered. This factor is even more apparent in a universe in which new religious movements are expressed in unusual and syncretic forms, but it also appears within the Catholic ecclesiastical context. Nonetheless the internal articulation of beliefs, meanings and religious practices appears to be rather jagged. Even more so if an attempt is made to investigate the religion and religious practices of the younger generations. In Italy, national and local research has shown how high levels of adhesion to Catholicism can be found in the population of youngsters, a figure that documents how the religion of prior generations is still a very important cultural reference in this country even for younger cohorts (Garelli, Guizzardi, \& Pace, 2003). Despite this, on many occasions, nominal affiliation does not follow through consistently in expected practices. The topic "youngsters and religious practice" is therefore a vital element of study and investigation in order to understand what some authors have defined as the "brainteaser" of Italian secularization (Diotallevi, 2001).

The sociological meaning of the words "youngsters" or "youth" is not an entirely clear one. Who are these people? Why do many studies limit the field of investigation exclusively to this portion of the population? From a biological point of view, there are no difficulties whatsoever in limiting the beginning of "youth" to the entrance into puberty, with regards to its conclusion, however, no similarly clear term exists to create discussion for post-adolescent (or interminably adolescent) persons. Moving onto discussions related to the social sciences, it is easy to see how the difficulties in providing a clear and unique definition increase drastically. "Adolescence" becomes a highly fluid concept, with indefinable boundaries and characteristics (Merico, 2005). A social researcher who plans to approach this area of study should take into consideration three characteristics: the complexity of the conditions of youngsters, the persistence across the years of typical characteristics of youngsters, and the continuation of exploratory methods of action on the part of this segment of the population.

Youth is a phase of life whose definition varies in time and according to different cultures. Many factors are included in this topic such as those of a biological, psychological and social nature. Youth is a temporary condition that "gradually marks the abandoning of typical roles of adolescence and the contemporary undertaking of functions and competences of the adult life” (Buzzi, Cavalli, \& de Lillo, 2007). Beginning after World War II and continuing to the present, lifespan has extended dramatically in the West, with a subsequent dilation in the time designated for "youth," with the anticipation of puberty at the start and delay of insertion into the adult world as the period extends. During the last century, forty-year olds were considered old; today fifty-year olds are still young.

As a result, "youth" does not mean from a social point of view, only those born in the same year, as stated by Karl Mannheim (1952), the first author to provide a sociological definition to the concept of generation and the consequent social unction of youth. Youngsters are those with a generational bond, created when "real social and spiritual contents form a real bond between individuals in the same generational group in 
the field of old and new" (Zurla, 1999). The first consequence of the extension of youth was the continuation of an economically nonproductive phase of new generations. Youngsters enter the world of employment at a later stage. The period of university studies is longer, and many Italian youngsters tend to move away from home at a later date compared with their European colleagues. In some cases the extension of adolescence creates a form of social absence of responsibility in a growing number of youngsters, often stable in a situation not so much of freedom but of marginalization. It is also true to say that the current employment and social situation in Italy does not help youngsters in reducing the postponement of phases from childhood to adulthood. In the last decades, the general level of production of jobs in Italy been well below the availability of works, therefore creating "high and chronic acts of unemployment in youngsters, for which easy solutions cannot be seen as a real economic model of development has been found without the creation of new jobs" (Donati \& Colozzi, 1997). If on the one hand this creates a condition of discomfort and uncertainty, especially in the higher age groups, on the other hand it does not lead to a gradual dejection of the faith of youngsters in the future. The majority of young Italians claim that they are happy with their lives, and if they wait even longer before moving away from home, the reason in the majority of cases is the growing level of independence and freedom that new generations currently have within the home context compared with to of the past.

To what extent, then, can we speak of the existence or nonexistence of a youth culture (or subculture), in contrast to or interpenetration with that of an adult culture? The expansion in time of youth has not only resulted in an increase in the number of individuals belonging to this demographic group but also a qualitative differentiation from a cultural point of view. If during the 1970s this difference reached its highest peak, now on the one hand some authors tend to focus on a growing interpenetration among various lifestyles, ways of thinking and behaving on the part adults coinciding with those of youngsters, with a subsequent dissolution of "youth culture" and a progressive alignment of both lifestyles (Donati \& Colozzi, 1997). On the other hand, some authors speak of a huge fissure that has opened up between the generations, due to the amount of income available to youngsters and their increasing mastery in the use of new technologies. On the other hand, Alessandro Cavalli (Cavalli, 2007) argues that no sign of generational conflicts currently exists. On the contrary, in some cases youngsters defend the status quo. There is no doubt that a youth lifestyle exists that is characterized by truly unusual cultural aspects such as, for example, methods of communication (e.g., the language used in text messages) or the creative use of new technologies, but this does not mean that the adult world does not know how to dialogue or does not try to adapt to these transformations, that the two realities are not united or that they clash. On the contrary, they communicate and dialogue in a relationship of reciprocity. From these discussions, we can understand how difficult it is in the social sciences to provide a substantive definition of youth and youth culture. The processes of psychosocial growth are positioned beyond rigid biological layouts, and the social scientist must analyze and interpret this fluidity in order to illustrate the characteristics, transformations and contradictions.

The concept of religious practice itself is similarly in flux. On the one hand, practice is one of the five dimensions of re- ligiosity. If religion is, in reality, a range of "beliefs and feelings of all kinds related to relations of man with a human being whose nature is considered above his own” (Durkheim, 1912), religiousness consequently refers to the empirically observable concrete forms through which individuals and groups express the various dimensions of religion itself. The multidimensional aspect of the term, due to the various possibilities of expression of the religious dimensions, logically follows. Various forms of religiousness, deriving from culture and from the forms proposed by the religious institutions, are generated from human methods of acquainting the self with the divine exist within every religion.

In the research discussed in this article, attention has been focused on the dimension of the religious practice, specifically the in the younger generation. The French sociologist Gabriel Le Bras in his Etudes de sociologie religieuse states that "practice expresses the life of a church" (Le Bras, 1955). In time, every religious institution has created "ritual" requirements that followers must observe so that their adhesion to belief is visible and controllable. Every religion includes, on the one hand, a whole series of beliefs, and on the other hand a certain number of practices or, anthropologically speaking, rituals. As Radcliffe Brown has suggested in an attempt to understand a religion we should start by concentrating our attention on rituals rather than beliefs (Brown, 1952). It is in practice that individuals experience the level of collective compulsion that the much more broader social-religious context can implement. Taking part in a collective ritual stimulates a feeling of identification with the community of belonging, common values are shared, and we feel a part of the same destiny (Cazeneuve, 1971). The "social-graphical" study of measuring religious practice therefore considers the latter as a "synthetic expression of vitality of the ritual and of the myth, therefore indirectly of everything that is sacred, and as one of the criteria of analysis of the religious vitality of a population” (Acquavivia, 1981). As far as Gabriel Le Bras is concerned, if we ignore "the number of followers, the places of cult, the participants [...] study of the doctrine will have a reduced effect, but the study of social groups and social relations risks getting lost in something that is abstract. Religious statistics provide us with an opportunity for an alliance between exact science and human science” (Le Bras, 1955). The majority of classical texts of sociological thought on religion have also attributed a strong symbolic and aggregative value to rituals and connected practices. "In the ritual, the lived world and the imaginative world, joined together by means of a single series of symbolic forms, are the same world, therefore an idiosyncratic transformation of reality is created" (Geertz, 1973). The same beliefs and religious practices find their origin in the "effervescence" of everyday contacts between men and being a cognitive and expressive representation of social relations they form a collective conscience.

All of this has undergone a clear transformation with the advent of the modern secularized societies. Religious practice has undergone a drastic re-dimensioning, especially in Europe. In particular, the abandonment of churches increases proportionally with the increase in age of the individuals; from a very high level of practice in pre-adolescents we can move onto a quick and often drastic abandonment in the years immediately after. Throughout the years this phenomenon has led researchers and the ecclesiastical hierarchies to ask themselves several questions such as: Is the fall in religious practice in youngsters a sign of a religious experience whose contents are weak? Is the 
increase in the number of abandonments of religious practice an alarm of the end of the religious message within the society? Only facts can answer these questions. There is no doubt that frequency at religious activities, especially by youngsters, has undergone a form of re-dimensioning across the years, but it is clear to everybody that religion, especially in the case of Italy, is far from dead. The reduction in practice does not automatically lead to a loss in religiousness of a society; the methods of understanding participation in celebrations have simply changed: They are no longer seen as duties that are coercively defined by a hierarchy, but they become behaviors of participation and communion only for those who intend to express openly their belonging to a church. If, on the one hand, the picture of going to church as a sign of conformism, especially in small districts where going to mass on a Sunday is an integral part of being a "good boy" because "otherwise people will talk" is still alive among the elderly, it no longer exists in new generations. Nevertheless, despite the fact that some still proclaim the end of religion, basing their discussions on the decline of practice, "the religious dimension survives in the context of a secularized society, it still produces a practice and is still related to the collectivity of believers: and this happens in a totally unexpected manner compared with the historical inclination of religious practice constantly falling with the progress of lay beliefs in conscience and individualism of behaviors" (Abbruzzese, 2000).

\section{The Participation of Youngsters in Religious Practices in an Italian Province}

\section{The Context and Conditions of the Research}

The religiousness of youngsters has been the subject of much national research in Italy, from which it has emerged how young Italians express their faith by emphasizing their interior, personal and emotional dimensions within their participation in practices and group activities. Nevertheless, due to historical and cultural reasons, Italy internally consists of a varied territorial reality. The Central-Southern area has not abandoned its traditions and customs that are still passed down from one generation to another. It is not by chance, for example, that the number of civil weddings is higher in the North than in the South. Being a youngster in Milan is not the same as being a youngster in Naples or Rome. The research was conducted in the central Italian region: Lazio. In the last fifteen years the Lazio region has undergone a transition from a local-provincial context to a globalized context. The terminal that connects the territory of central Italy to the rest of the world is city of Rome. This city, being both historical and sacred, has been transformed into an exchange point of the global economy. The same strengthening of airports of Rome similarly increased proportionately to create space for the constant ongoing traffic of passengers, represents concrete proof of the presence of a global terminal. Not all areas of the Lazio region are in the same conditions, however. In this region the population includes two extremes: marginalization in the area of the Apennines, where old traditions still exist, even though Italian shepherds in this area are now replaced by Albanian shepherds, right up to the Roman area where the emergency due to population influx is permanent also from a sanitary point of view, such as the Esquilino. In these two territorial realities, especially after the Second World War, on the one hand, an intense process of modernization occurred, especially behind the large roads of communication coinciding with the major centers of the provinces, on the other hand, the smaller centers, in particular those such as Frosinone behind the chain of the Apennines, have gone through a high level of emigration with the gradual emptying of town centers in which the air of a small ancient world can still be breathed.

\section{Methodology}

The study was conducted at the provincial area to the South of Rome: the provinces of Frosinone and Latina. A number of methodologies were implemented to suit the inductive and multi-indicator approach of the study. The design and methods are summarized briefly; a detailed description is available elsewhere (Meglio, 2010). The study involving a sample of 1225 youngsters and young adults between 14 and 35 years of age. The investigations carried out are quantitative, and the survey was carried out directly and anonymously, using trained interviewers. Respondents completed self-report surveys (using a paper-and-pencil format) administered by the author and trained graduate students in school during school hours (for the students interviewed). All adolescents received parental permission to participate. Religion, as treated here, is a multidimensional construct consisting of attitudinal (i.e., importance), behavioral (i.e., church attendance), and organizational (i.e., affiliation) components. Below will expose only the data related to religious practice.

\section{Results}

If on the one hand, the ecclesiastical hierarchies note the need to emphasize the importance of participation in Sunday mass, data on the presence of youngsters in the lower Lazio region confirm the national and European trend. Twenty-seven percent of all people interviewed go to Sunday mass; the plurality, $48.6 \%$, confirm that they go to Church only on holy days and special occasions such as weddings, baptisms and other ceremonies. Twelve percent, not an excessively low figure, declare that they go to Church more than once a week, while $10 \%$ never go to Church. If we compare these data with national research carried out by the IARD Institute of Milan we can see that the figures are not so different, in this case $17.2 \%$ of all youngsters interviewed go to Church every Sunday. Therefore, the trend that sees young Italians going to Sunday mass less and less is confirmed. Catholic church-goers are replaced by "anonymous Catholics" - that is to say, the trend is to take part less and less in religious ceremonies, while people make contact with everything sacred and religious in a personal and intimate manner. As far as gender differences are concerned, we can see how girls are much more involved in religious phenomenon, a larger number of them take part in Sunday mass compared with boys, who register a much lower level of participation in Sunday mass, perhaps only on special occasions. Figures on Sunday participation are also confirmed by the answers given to the question on participation in rites (Christmas, Easter) of their own religion-23.3\% replied always, $28.5 \%$ often, $33.7 \%$ (the majority) every now and again, and $14.3 \%$ never.

The subject of religious practice has always included the commitment of the ecclesiastical hierarchy. In a recent public audience Pope Benedict XVI emphasized the need to partici- 
pate in Sunday mass. In Catholic doctrine, Sunday is the day that Christians meet together to proclaim their faith and feed on the Word of God and the Eucharist. Without participation in the Table of Faith and the Table of the Eucharist, there is no chance that the Church will survive. Sunday is the day that the Church stands out. The first Christians used to meet on Sunday, as can be seen from the following words: "On the first day of the week we used to meet up to break the bread" (Acts 20:7). It was not a one-off meeting but a habit that had become a tradition. The ecclesiastic hierarchies are therefore very well aware of the reduction in Sunday practice between the population and the followers, especially among the new generations. Sundays have become days that are not so different from other days of the week. A sense of Sunday and its vital importance for Christian life is experienced by participants in the liturgy, but it is less the case that these participants and the civil community are one. Religious participation does not end with going or not going to church on Sunday. Life inside the church is articulated in various moments, groups and associations in which the participants share with those next to them, experiences of aggregation and the sharing of common values. Once religion has been institutionalized, it becomes an organization with internal rules and structures that punctuate life and in which processes of formation and legitimization of the symbolic contents are passed down from one generation to another. The religious organizations become complex networks through which the experience and religious actions are formed, structured and sustained across time, if the religious experience is an immediate and deep experience in which God appears to be present in the soul, in which the eruption of divinity is experienced internally or in the community; inevitably the organization is the second moment, the moment of mediation of that experience.

Throughout the years many associations or groups of Catholic inspiration have been formed with the objective of favoring hospitality, integration and religious socialization of youngsters from a very young age. Oratorians are an example. Named from the Latin word orare (prayer), they were born as small areas of cultus where followers met for group prayer. It was St. Philip Neri in 1550 who founded the first modern oratory, whose objective was to create a community of believers joined by a spirit of human charity. It was with St. John Bosco (1853) that groups among youngsters were created. The oratory became an arena for religious life as well as human interaction and training. The model was extended to the local parishes, where alongside the formal liturgies of the Church, small meeting areas were created for youngsters.

The most ancient and diffused lay Catholic association in Italy is Catholic Action. Born following the initiative of two university students in 1867 with the name of "Society of Catholic Youth," throughout the years the association grew rapidly and was diffused among parishes throughout Italy, from the North to the South. In principle it was divided into male and female sections, though this division was eliminated through the years. The motto "Prayer, Action, Sacrifice" summarizes loyalty to the various Catholics of the universal Church. In 1919 a group of the Catholic association founded the community of Boy Scouts in Italy. Founded in 1907 in England by Robert Baden-Powell, the Scouts represent a young worldwide movement, with the declared objective of educating youngsters and helping them in their physical, mental and spiritual development. It was born in Italy following a Catholic initiative, and it currently has almost 177,000 members. Other religious vo- luntary activity groups also exist, such as Caritas, present in all diocesan locations and aimed at helping the less well-off or the physically disabled and catechesis activities that every parish offers to children along their religious growth. Therefore a network of groups and associations form the organizational "machine" of the Church as a community for prayer, help and socialization: "the Catholic movement is therefore configured as an answer to marginality in which modern society has confined the religious institution" (Abbruzzese, 1991). "In which of these activities do the youngsters of the Lazio region take part?” is another question that has been asked in this investigation. The figures are not too encouraging (Table 1).

Participation in these activities is very low and obviously of a female predominance, Catholic Action registers $15.3 \%$ of participants and catechism $11.9 \%$, the figure that refers to youngsters who follow the course for the sacrament of Confirmation. Even though the figures are not entirely unexpected, in reality it contrasts against the territorial heritage, considering most of all the realities of the town, where life substantially rotates around the parish community, perhaps having lost attraction with regard to new generations.

In order to investigate this figure in greater detail-in particular, in an attempt to understand the reasons that lie at the basis of participation or lack of participation in these activities, the question was asked, "What led you to become a part of a religious group or association?” The plurality of youth who take part in these activities have stated that friendship is the most important reason for their inclusion in these groups. Secondarily they were stimulated by their religious belief (Table 2).

Therefore, being in the company of friends is the main reason that motivates youngsters to take part in the activities of these associations. In towns that do not have much to offer in

Table 1.

In which of this activities do you take part?

\begin{tabular}{lccc}
\hline \multirow{2}{*}{ Activities } & \multicolumn{3}{c}{ Responses } \\
\cline { 2 - 4 } & Yes (\%) & No (\%) & Total \\
\hline Oratory & 9.9 & 90.1 & 100.0 \\
Catholic action & 15.3 & 84.7 & 100.0 \\
Catechism & 11.9 & 88.1 & 100.0 \\
Caritas & 8.9 & 91,1 & 100.0 \\
Scouting & 6.0 & 94.0 & 100.0 \\
\hline
\end{tabular}

Table 2.

Reasons for participation in religious groups.

\begin{tabular}{lc}
\hline \multicolumn{1}{c}{ Reasons } & Responses (\%) \\
\hline Friendship & 23.3 \\
Escape from the family & 3.0 \\
Loneliness & 2.1 \\
Need to act on a social level & 9.2 \\
Investigate into faith related problems & 6.7 \\
Form a personality & 6.1 \\
Experience & 8.7 \\
Religious belief & 13.0 \\
\hline
\end{tabular}


terms of pleasure, getting together in groups or associations is the only place for them to socialize.

\section{Conclusion}

The survey carried out in the lower area of the Lazio region, even with the methodological limits previously indicated, has allowed us to identify, through the analysis of religious practice, some important aspects of the religious orientation of the new generations of this territory. The Catholic religion remains the most important confession due to historical, social and cultural reasons. Faith alone is not in discussion. Contrary to those who state the disappearance of the religion from modern society, it is still alive and present. Obviously this does not mean that there have not been changes in the dynamics of destruction/rebuilding of belief. Religious institutions are going through a period of constant crisis, as can be seen from figures on practice and participation in community rituals. The churches are seen as the guardians of large common values, in which everybody recognizes himself or herself. The theories on cultural relativism are contradicted. In terms of value it is not true to say that everyone can have his or her own personal opinion, Common values exist that are given by tradition and are commonly accepted, but beyond the ethical-cultural function the Church is excluded from the most intimate and personal sphere of each individual moral actor. Using the words of Boudon (Boudon, 2002), the pre-concept principles are no longer used in an unconditional manner, but they are used by re-modeling them, discussing their validity before using them.

Religion in Italian society is not dead. On the contrary it is very much alive, present and alert. Like a liquid that pours into a solid object and models itself according to the shape, religion has been capable of modeling according to the great and constant transformations that "late modernity" has provided to the life of each individual. The new generations have powered this transformation despite the difficulties of youngsters in Italy, with their problems and discomforts, with their undeniable resources and potentials, with the questions and doubts constantly asked. These difficulties cannot be attributed to deep changes that may have occurred within the society in the last few decades. The advent of new technologies and forced modernization have generated drastic changes with consequences on current mentalities and lifestyles. As far as "thinking" is concerned, it is important to point out that with the fall of the grand narratives that occurred recently, so-called "weak" thought has become more and more important, with the new generations representing privileged victims. This is the society of the image, of appearance, where commitment for reflection and thought has been overcome by a totalistic use of the computer. The constant flow of images and sounds arouses strong emotions. Youth "freak out" during long nights in discos. They meet on Facebook, but they lose the pleasure of getting lost in a real smile (Meglio, 2010).

Once the strong experience is over, once the computer has been turned off, then we realize that there is a guest always present in the life of youngsters: solitude. At this point many questions arise for themselves, on the world, on society: it is at this time that we realize that nobody is there to provide answers. At this point the problem of communication between the generations arises. Communication problems between parents and children are very frequent by both sides, and this is not due only to the clear age gap, but also to the consequent incapacity of authentic communication that can embrace the inevitable differences. On the one hand, the search is for lifestyles that are closer to personal ones; on the other hand, youngsters tend to remain at home due to the undisputed economic benefits.

This picture, even though it is realistic, has highlighted the negative elements present within the current universe of youngsters. Luckily positive elements also exist. In many cases the total absence of values in today's youngsters can be found. By observing them and entering their world, there are very few positive signals, but they stimulate an optimistic hope for the future; it is important to simply accept and enhance them. This is basically what emerged from the various Italian surveys. First, there is a diffused demand for defence with regards to the values that form society: attachment to the land of origin, innate generosity and opening up toward new cultures, highlighting solidarity that is not aware of barriers, and finally a request for "freedom" understood as the ability for self-realization through personal potentials (Meglio, 2011). Once again, the family remains the first agency of religious socialization. Almost all infants have a familiarization with religion; as the years pass religious beliefs tend to disappear-but not in terms of a refusal or doubting of vital values, but postponement for a later stage of life where contact with the transcendent acquires greater meaning. Despite the secularization process that for half a century has ratified within Italian society the marginality of everything that is sacred, as broadly shown in various surveys, the youngsters of the Lazio region confirm that they are believers. Obviously it is one thing to claim to be religious, while it is another thing to claim to be a "religious person," attentive to following their religious beliefs through a lifestyle. Scholars speak of the "interiorization" of religious beliefs: Creed is transformed from public to private. Relationships with everything that is sacred assume a spiritual and subjective nature (Luckmann, 1963). "Do-it-yourself” religion has been born, without necessarily being subject to norms and obligations deriving from a religious institution. These could almost be defined as "anonymous Catholics," meaning that they state that they are believers and belong to the "official" religion, but they pray and they are totally anonymous in their belief. Figures on practice in our case also confirm the national trend-therefore a drastic fall in participation in rituals, especially on Sundays: the "controlled" feasts still survive.

\section{REFERENCES}

Abbruzzese, S. (1991). Comunione e Liberazione: Identità religiosa e disincanto del laico. Bari, BA: Laterza.

Abbruzzese, S. (2000). Il posto del sacro. In La via italiana alla post-modernità. Verso una nuova architettura dei valori (pp. 397455). Milano: Franco Angeli.

Acquavivia, S. (1981). L'eclissi del sacro nella civiltà industriale: Dissacrazione e secolarizzazione nella società industriale e postindustriale. Milano: Comunità.

Boudon, R. (2002). Decline de la morale? Declin des valeurs? Paris: Paris University Press.

Brown, R. (1952). Structure and function in primitive society. New York, NY: Cohen \& West.

Buzzi, C., Cavalli, A., \& de Lillo, A. (2007). Rapporto giovani: Sesta indagine Iard sulla condizione giovanile in Italia. Bologna: Il Mulino.

Cavalli, A. (2007). Introduzione. In Rapporto giovani. Sesta indagine Iard sulla condizione giovanile in Italia (pp. 19-29). Bologna: Il Mulino.

Cazeneuve, J. (1971). Sociologie du rite. Paris: Paris University Press. 
Diotallevi, L. (2001). Il rompicapo della secolarizzazione italiana. Soveria Manelli: Rubbettino.

Donati, P., \& Colozzi, I. (1997). Giovani e generazioni: Quando si cresce in una società eticamente neutra. Bologna: Il Mulino.

Durkheim, É. (1912). Les formes élémentaires de la vie religieuse. Paris: Alcan.

Garelli, F., Guizzardi, G., \& Enzo, P. (2003). Un singolare pluralismo. Indagine sul pluralismo morale e religioso degli italiani. Bologna: Il Mulino.

Geertz, C. (1973). The interpretation of cultures. New York, NY: Basic Books.

Le Bras, G. (1955). Ètudes de sociologie religieuse. Paris: Presses
Universitaires de France.

Luckmann, T. (1963). Das problem der religion in der modern Gesellenshaft. Freiburg: Rombach.

Mannheim, K. (1952). Essays on the sociology of knowledge. London: Routledge.

Meglio, L. (2010). Società religiosa e impegno nella fede: Indagine sulla religiosità giovanile nel basso Lazio. Milano: Franco Angeli.

Meglio, L. (2011). Religione. In I concetti fondamentali del sapere sociologico (pp. 295-304). Milano: Franco Angeli.

Merico, M. (2005). Giovani e società. Roma: Carocci.

Zurla, P. (1999). Giovani e lavoro. Rappresentazioni e percorsi. Milano: Franco Angeli. 